European Journal of Social Psychology

Eur. J. Soc. Psychol. 37, 1032-1045 (2007)

Published online 2 January 2007 in Wiley InterScience

(www.interscience.wiley.com) DOI: 10.1002/ejsp.416

\title{
Nonconscious influences of religion on prosociality: A priming study
}

\author{
ISABELLE PICHON ${ }^{1 *}$, GIULIO BOCCATO ${ }^{1,2}$ \\ AND VASSILIS SAROGLOU ${ }^{1}$ \\ ${ }^{1}$ Catholic University of Louvain, Louvain-la-Neuve, \\ Belgium \\ ${ }^{2}$ Università degli Studi di Padova \& Università di \\ Verona, Italy
}

\begin{abstract}
Past literature on the automaticity of social behavior indicates that priming a concept automatically activates related behavioral schemas. In the two present studies we examined the impact of religion on prosociality. In the first study, we tested the impact of subliminal priming of religious concepts on prosocial behavior intentions. We found a main effect of this priming, moderated by valence: prosocial behavior tendencies were stronger when positive religious words had previously been subliminally primed. In the second study, we examined the accessibility of prosocial concepts, after the supraliminal activation of religion. Indeed, we found that not only were religion-related attributes more accessible when primed, but positive religious primes were also able to activate prosocial concepts. While previous research has shown the religion-prosociality link at the explicit level and in terms of the role of individual religiousness, these results indicate that religious concepts by themselves can nonconsciously activate prosocial behavioral schemas. Copyright (C) 2007 John Wiley \& Sons, Ltd.
\end{abstract}

Most psychological theories of religion assume that religion plays an important role on prosocial behavior. Religion as a part of culture helps individuals to face the destructiveness of nature and the dangerousness of people's egoistic impulses (Freud, 1927/1961). Saints are persons who, by setting the example of charity, make possible what seems risky, pragmatically speaking, because such charity is in principle against one's own personal interests (James, 1902/1985). Religion implies ideals of generativity and concern for others and for subsequent generations (Erikson, 1963). It further provides specific reinforcements and punishments in order to foster moral, prosocial behavior (Skinner, 1969). From a sociobiological and evolutionary perspective, religion is hypothesized to extend the limits of

*Correspondence to: Dr Isabelle Pichon, Université de La Réunion, Faculté des Sciences de l'Homme et de l'Environnement, 117 Rue du Général Ailleret, 97430 Le Tampon, Ile de La Réunion. E-mail: Isabelle.PIchon@univ-reunion.fr 
altruism applied to natural kinship toward broader borders of cultural kinships (Batson, 1983) and to solidify large coalitions and reciprocated cooperative behavior (Kirkpatrick, 2005).

Empirical investigation provides only partial and indirect support to the idea that religion has an impact on prosocial behavior, and a complex pattern of results sometimes even disconfirms this idea. On one hand, studies using self-report measures confirm a rather systematic finding across cultures, religions, and cohorts that intensity of religiousness is positively - although weaklyassociated with prosocial personality traits and values or with helping behavior (Batson, Schoenrade, \& Ventis, 1993; Saroglou, 2002, in press; Saroglou, Delpierre, \& Dernelle, 2004). On the other hand, studies using social-experimental designs found that prosocial behavior as a function of religiousness is limited to particular religious orientations and to low- rather than high-cost requests. Further, it often reflects an egoistic (concern for a positive self-image) rather than altruistic motivation (Batson et al., 1993; Batson, Anderson, \& Collins, 2005). Religious people may even be discriminatory and unhelpful toward outgroup members (e.g., Jackson \& Esses, 1997; see also Hunsberger \& Jackson, 2005).

Integrating the results from previous studies, Saroglou, Pichon, Trompette, Verschueren, and Dernelle (2005; Saroglou, 2006) argued that prosociality in the context of religion does exist (it is not only a component of self-perception) although it is limited in extent and scope. Indeed, Saroglou et al. (2005) found that religious people are not self-delusional when reporting high prosocial concerns and altruism - peers validate such tendencies (Studies 3 and 4) — and that religiousness is accompanied by a 'minimal' prosociality such as low aggression and propensity for helping close but not unknown targets (Studies 1 and 2). Such a link between religion and prosociality is also indicated by the results of de Dreu, Yzerbyt, and Leyens (1995): in a prisoner dilemma game, the participants (students) tend to cooperate more, expect their peer to be more cooperative, and find this peer more honest and moral when $\mathrm{s} / \mathrm{he}$ is presented as a religion major than a business major. We could thus consider that the link between religion and prosociality is, to some extent, real: prosociality is an element of the representation of religion and the activation of the latter may have an impact on some prosocial behaviors.

One important limitation of most previous studies was that paper-and-pencil measures were used: prosociality was measured in terms of self-reports, peer-ratings, or projective behavior. With the exception of some rare studies (see Batson et al., 1993, for review), research on religion and prosociality has rarely investigated behavior per se. More importantly, all of the above-mentioned studies used explicit measures. Explicit measures are based on overt answers, and consequently they are potentially biased by direct control from individuals as well as by external variables that may interfere with evaluative processes. Conversely, implicit techniques are efficient in assessing concept structure from memory, without directly asking individuals for an oral or written report (Fazio \& Olson, 2003). The major appeal of implicit techniques is their independence from social desirability concerns, which may be of particular importance for the religion-prosociality association given the well-established tendency of religious people toward high social desirability (Trimble, 1997). One such implicit measure of the religion-prosociality association may be the increase in accessibility of prosocial thoughts after exposure to a religion prime.

Another important issue that has been rather unexplored is causal direction. Almost all previous studies - ones based on self-reports and peer-ratings as well as ones using a social-experimental design - provide only correlational information, strictly speaking: one or another dimension of individual religiousness was positively associated with one or another prosocial behavior or construct. We spontaneously tend to assume that such a correlational link must be considered as indirect evidence in favor of a causal role of religion on prosocial behavior. However, the issue of causal direction, with religion or at least some of its aspects as an antecedent and somewhat influencing people to behave or at least to think in a prosocial way, remains unexplored. 
The aim of the present study is thus twofold: (a) to overcome the limits of explicit measures by using behavioral and accessibility measures of prosociality, and (b) to assess the direct impact of religion as an independent variable on prosocial intentions and related construct accessibility, after priming religion and investigating subsequent prosocial reactions. Over the last 25 years scholars in psychology have shown that priming social norms, goals, emotions, and stereotypes can nonconsciously guide subsequent responses and behaviors (Bargh, 2006; Dijksterhuis \& Bargh, 2001). For instance, when people are primed with words related to the elderly stereotype, they walk significantly slower than control participants (Bargh, Chen, \& Burrows, 1996, Experiment 2); people primed with photographs of African Americans display more hostile reactions than people primed with Caucasian faces (Bargh et al., 1996, Experiment 3); and priming the professor concept prompts students to answer more questions correctly than control participants (Dijksterhuis \& van Knippenberg, 1998).

It seemed reasonable to us to expect, first, that prosocial concepts and behavioral schemas may be activated through priming. For instance, Macrae and Johnson (1998) found that the tendency to offer assistance (to an experimenter) increased when participants were primed to be helpful — at least when no inhibitory cues were present in the environment. Nelson and Norton (2005) found that participants primed with the category superhero (but not participants primed with the extreme exemplar, Superman) saw themselves as more likely to help in hypothetical situations and indeed as more committed and engaged in volunteering. Second, a few previous studies indicate that religious stimuli presented without participants' awareness may be effective in producing some reactions assumed or known to be in line with religion. Baldwin, Carrell, and Lopez (1990) found differences in self-evaluation following subliminal exposure to a religious image (the Pope), and Wenger (2004) found that participants identify actions expressing religiousness faster after being primed with an appropriate religious category. Thus, we predict that a religion prime should also be efficient in producing prosocial tendencies. Indeed, if religion is associated with altruism, quality of interpersonal relationships, and compassion, then religious concepts, ideas, images, and acts should evoke behavioral or perceptual responses in accordance with the altruistic ideal. Furthermore, Weisbuch-Remingtion, Mendes, Seery, and Blascovich (2005) found that subliminal exposure to religious symbols influenced cardiovascular responses differently depending upon whether these symbols were positive or negative. Following this result, only religious concepts that were positive and neutral in valence (e.g., not threatening) were used in the present studies.

\section{OVERVIEW}

In sum, in the present studies our aim was to test the link between religion and prosociality, without the possibility of explicit control over responses, by investigating the impact of religion priming on subsequent reactions. The two studies reported in the present article used both a behavioral and an accessibility measure. Specifically, in Study 1, religion-related words as well as control words (both neutral vs. positive in valence) were used as subliminal primes, and the number of charity pamphlets taken by the participant before leaving the laboratory was counted and used as the dependent variable. We expected participants primed with religion concepts, and especially positive religion concepts, to show stronger prosocial behavioral intentions (more pamphlets taken). Probably, this could be because religion may lead to an increased accessibility of prosocial schemas. In Study 2, we directly examined this last prediction, that is, after participants were primed with religion or control words through a word-search puzzle, accessibility of prosocial related items was assessed using a lexical decision task. In line with previous results, we hypothesized that participants would be faster at identifying prosocial items following a religion prime, especially a positive religious one, than a control prime. 


\section{STUDY 1: PROSOCIAL BEHAVIOR}

\section{Procedure}

Ninety-one psychology students from the Catholic University of Louvain (Louvain-la-Neuve, Belgium), took part in the study in order to fulfill course requirements. Participants performed a lexical decision task aimed at subliminally priming religion-related versus religion-unrelated words. Afterwards, and before leaving the laboratory, each participant was free to take as many pamphlets about charity actions as s/he wanted. The study had a 2 (Prime Type: religion-related vs. religion-unrelated) $\times 2$ (Prime Valence: positive vs. neutral) full between-subjects model. Forty-four students received religious primes ( 22 were in the positive religious prime condition and 22 in the neutral religious prime condition) and 47 students received primes unrelated to religion ( 24 were in the positive prime condition and 23 in the neutral condition).

\section{Prime Pre-test}

Another forty participants from the same kind of population had previously evaluated 154 words according to their valence and to religious connotation. The order of the task (valence and religiosity) was counterbalanced. Both valence and religiosity were evaluated through a Likert-type scale ranging form 1 to $7(1=$ negative and $7=$ positive, for valence; $1=$ not related to religion and $7=$ related to religion, for religiosity). Using one-sample $t$-test statistics, we selected words that were related or unrelated to religion as well as positive and neutral words at the same time. So we had four types of words (see Appendix A): (a) positive religion-related words (significantly higher than the middle point of valence connotation), (b) neutral religion-related words (not different from the middle point of the valence scale), (c) positive words unrelated to religion (significantly higher than the middle point of the valence scale), as well as (d) neutral words unrelated to religion (not different from the middle point of the valence scale). Next, through paired sample $t$-test, words related and unrelated to religion were paired relative to valence.

\section{Lexical Decision Task}

Participants performed a task in which they were asked to make judgments about a set of letter strings presented on the computer screen. Participants were presented, at each trial, with a string of Xs followed by a letter sequence. They had to decide whether the target sequence formed a word or not: they were asked to press a 'Yes' key if the sequence corresponded to a word, and to press a 'No' key if the sequence did not correspond to a word. Participants were shown a total of 20 lexical decision trials and were asked to make their judgments as quickly and accurately as possible.

The procedure for the lexical decision task was adapted from Wittenbrink, Judd, and Park (1997, 2001). The experiment was programed using PSYSCOPE software (Cohen, MacWhinney, Flatt, \& Provost, 1993) and was run on an iMac computer. On each trial a fixation point appeared on the screen for $500 \mathrm{~ms}$, immediately followed by a prime. The prime appeared for $15 \mathrm{~ms}$ and was immediately overwritten by a mask (a string of Xs). This combination of short stimulus exposure and masking was used to insure that participants would remain unaware of the primes. After $500 \mathrm{~ms}$, the masking stimulus was substituted by a target letter sequence, which itself was erased after another $500 \mathrm{~ms}$. The computer then paused until participants gave their answer by pressing the appropriate key ('Yes' or 
'No'). The items consisted of 20 sequences of letters, more precisely 10 words and 10 non-words. The 10 words came from the list of the neutral words unrelated to religion detailed in Appendix A; the 10 non-words were anagrams of the former ones. All the 20 items - the same across conditions-were preceded by subliminal primes. In the positive religious prime condition, each letter string was preceded by a positive word related to religion (e.g., heaven). In the neutral religious prime condition, each letter string was preceded by a neutral word related to religion (e.g., parish). In the positive prime condition, each letter string was preceded by a positive word unrelated to religion (e.g., liberty). In the neutral prime condition, each letter string was preceded by a neutral (in valence) word unrelated to religion (e.g., shirt).

\section{Behavioral Measure}

After participants completed the lexical decision task, they were informed that they could take some pamphlets to increase sensitivity of a lay Belgian association (known as 'Restos du cour' in French) which provides food for disadvantaged people. The experimenter explicitly made the following statement: 'We'd like to take advantage of your presence here to remind you the importance of the "Restos du cœur" association. If you wish, you can take as many folders as you like and distribute them around you to contribute to the spreading of Restos $d u$ cœur's charity objectives. It is as you wish. Thank you'. In order to avoid self-presentation bias, the experimenter had the back turned while the participant was taking the pamphlets. The number of pamphlets taken was calculated after the participant's departure on the basis of pamphlets missing from the stack. After the two tasks were completed, participants were debriefed about the aim of the study. No participant was aware of the presence of a subliminal prime or of its nature.

\section{Results and Discussion}

Data were submitted to a two-way ANOVA 2 (Prime Type: religious-related vs. religious-unrelated) $\times$ 2 (Prime Valence: positive vs. neutral). The Prime Type factor came out significant: participants primed with religious words took more pamphlets $(M=5.73, S D=0.63)$ than participants primed with non-religious words $(M=3.59, S D=0.61), F(1,87)=5.89, p<.02$. No main effect of valence was observed. However, we found a two-way interaction between Prime Type and Prime Valence, $F(1,87)=6.08, p<.02$ : people primed with religious positive words took more pamphlets $(M=7.23$, $S D=5.50)$ than people primed with non-religious positive words $(M=2.92, S D=3.37), t(1,44)=$ $3.17, p<.01$, and people primed with neutral religious words $(M=4.23, S D=4.23), t(1,42)=2.02$, $p<.05$. In the neutral words conditions, however, there was no difference between religious $(M=4.23$, $S D=4.23)$ and non-religious $(M=4.26, S D=3.39)$ words, $t(1,43)=-0.03$.

Results thus indicate that people have more prosocial intentions when primed with religion-related words, but this is true when this type of words has a positive valence (see Figure 1). These results first confirm the impact of religion (at least, of some religious aspects) on prosociality (at least, on some prosocial intentions) and provide initial empirical evidence on one direction of causality beyond the well-established correlational link between religion and prosociality. Second, the results suggest that, rather than valence or religion as such, it is the combination of religious elements with positivity in valence that increases the likelihood of prosocial intentions. (Note that in the non-religious conditions, priming with positive words did not increase prosocial intentions compared to priming with words neutral in valence, $t(1,46)=-1.36$, n.s.; in addition, as mentioned above, the religion-neutral condition 


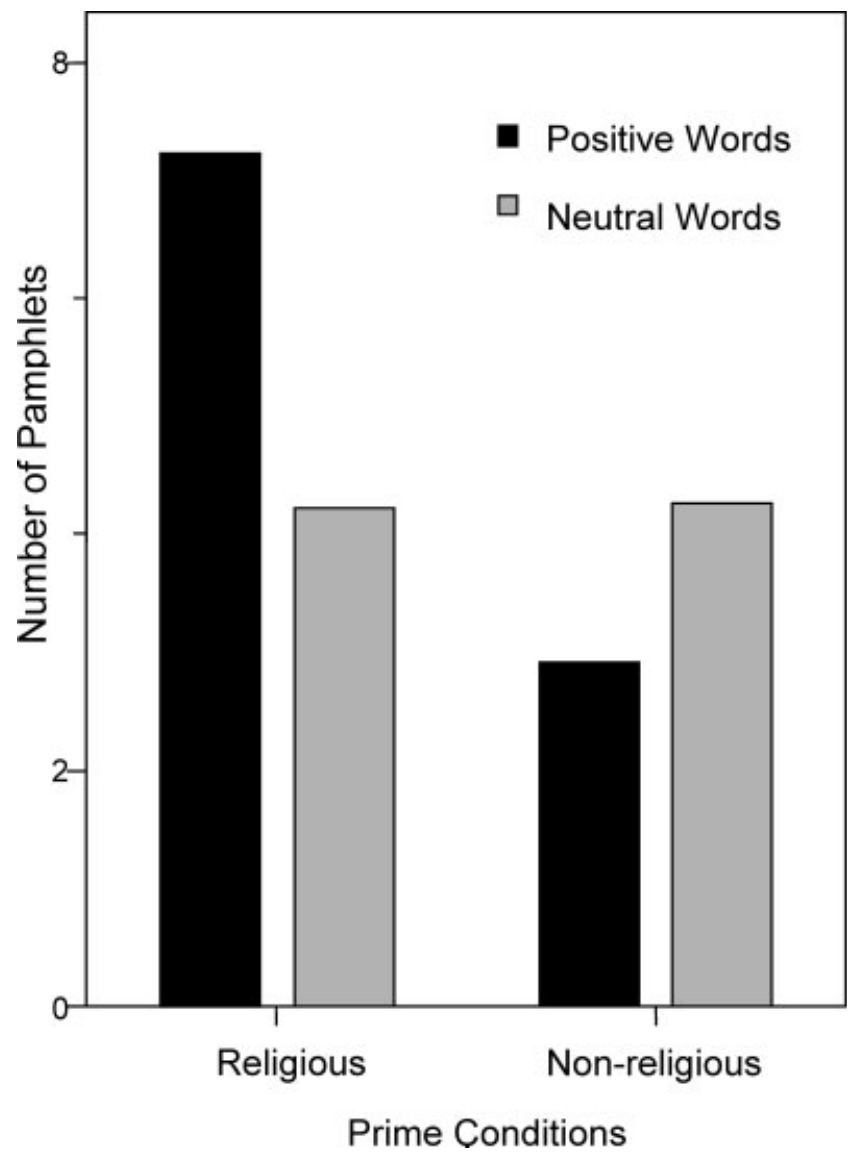

Figure 1. Number of charity pamphlets taken depending on prime type (Study 1)

was no more effective than the non-religious neutral one). In sum, only the positive side of religion is able to activate a prosocial behavioral schema.

Why does priming (positive) religion nonconsciously affect prosocial behavioral intentions? One possible explanation is that religion automatically activates prosocial concepts in people's minds. In Study 2, we thus tested whether priming participants with religious words would increase not only the accessibility of religious concepts but also the accessibility of prosociality-related concepts. On the basis of the results of Study 1, however, we expected that the latter would only be the case with positive religious priming whereas neutral religious priming would act more like a control (neutral and non-religious) priming.

\section{STUDY 2: PROSOCIAL ACCESSIBILITY}

\section{Participants and Design}

Fifty-seven psychology students from the Catholic University of Louvain at Louvain-la-Neuve took part in the study in order to fulfill course requirements. They were randomly assigned to one of three 
between-participant conditions. Participants, depending on the condition, were either primed with neutral religious words $(n=20)$ or positive religious words $(n=17)$ or control words $(n=20)$ via a word-search puzzle. Afterwards, all participants performed a lexical decision task (the same across the conditions) aimed at assessing the accessibility of religion- and prosociality-related concepts.

\section{Stimulus Material}

Participants were run individually by an experimenter, who explained that they would participate in a study about processing information. First, the priming manipulation was carried out through an initial word-search puzzle that each participant completed by him/herself. This task has already been used successfully to prime concepts without participants being aware of any particular concept having been activated (Bargh, Gollwitzer, Lee-Chai, Barndollar, \& Trotschel, 2001). A $9 \times 12$ matrix of letters was presented, and a list of seven words was shown; instructions specified that the seven words below were included in the matrix. Words could appear with letters in a straight line either from left to right or from right to left reading down or reading up, and diagonally reading either down or up. Four words were specific for each condition. In the control condition, we provided the words sun, flower, and charm (words were selected from the list of words unrelated to religion used in Study 1). In the neutral religion condition, we presented the words apostle, disciple, and incense. In the positive religious condition, we included communion, pilgrimage, and faith. Finally, in each condition, a list of words unrelated to religion and neutral in valence were added in order to distract participants' attention from the real purpose of the task (stairs, handkerchief, hammer, office).

After completing the word-search puzzle, participants performed a lexical decision task. Forty-two strings of letters appeared one at a time on the computer screen. Twenty-one were existing words (seven related to religion, seven related to prosociality, and seven fillers; see Appendix B), while the remaining items were anagrams of these words. The set of religion words was introduced in order to check that religious priming effectively activates religion-related concepts. The procedure of the lexical decision task was similar to that used in Study 1, except than the presence of primes and mask. Latencies were registered. At the end of the experiment, participants were dismissed and debriefed: no participant noticed the connection between the two tasks.

\section{Results and Discussion}

Incorrect responses and latencies that occurred faster than $150 \mathrm{~ms}$ or slower than $1500 \mathrm{~ms}$ were considered outliers and excluded from the analysis (see Wittenbrink et al., 2001). Between-condition comparisons were conducted, distinctly for religious and prosocial words. Results (see Figure 2) confirmed our expectations (on the basis of both uni-directional expectations and the results of Study 1, a one-tailed significance level was applied). Firstly, as far as the efficiency of our manipulation is concerned, participants who were primed with religious concepts (positive and neutral taken as a whole) performed the lexical task with faster responses on religion targets words $(M=307.48$, $S D=64.09)$ in comparison to non-religious control priming $(M=343.23, S D=99.64), t(1,55)=1.45$, $p<.04$. Second, religious neutral priming did not decrease latencies of recognizing prosocial items $(M=329.63, S D=110.59)$ in comparison to control priming $(M=315.27, S D=93.05)$; indeed, the latencies were rather similar between these two conditions, $t(1,38)=-0.44$, n.s. With regard to prosocial words, in line with Study 1, religious neutral priming thus seemed to function as a neutral, control priming. However, as hypothesized, latencies in recognition of prosocial words seemed to be lower when participants were primed with positive religion $(M=288.17, S D=59.82)$. Indeed, 


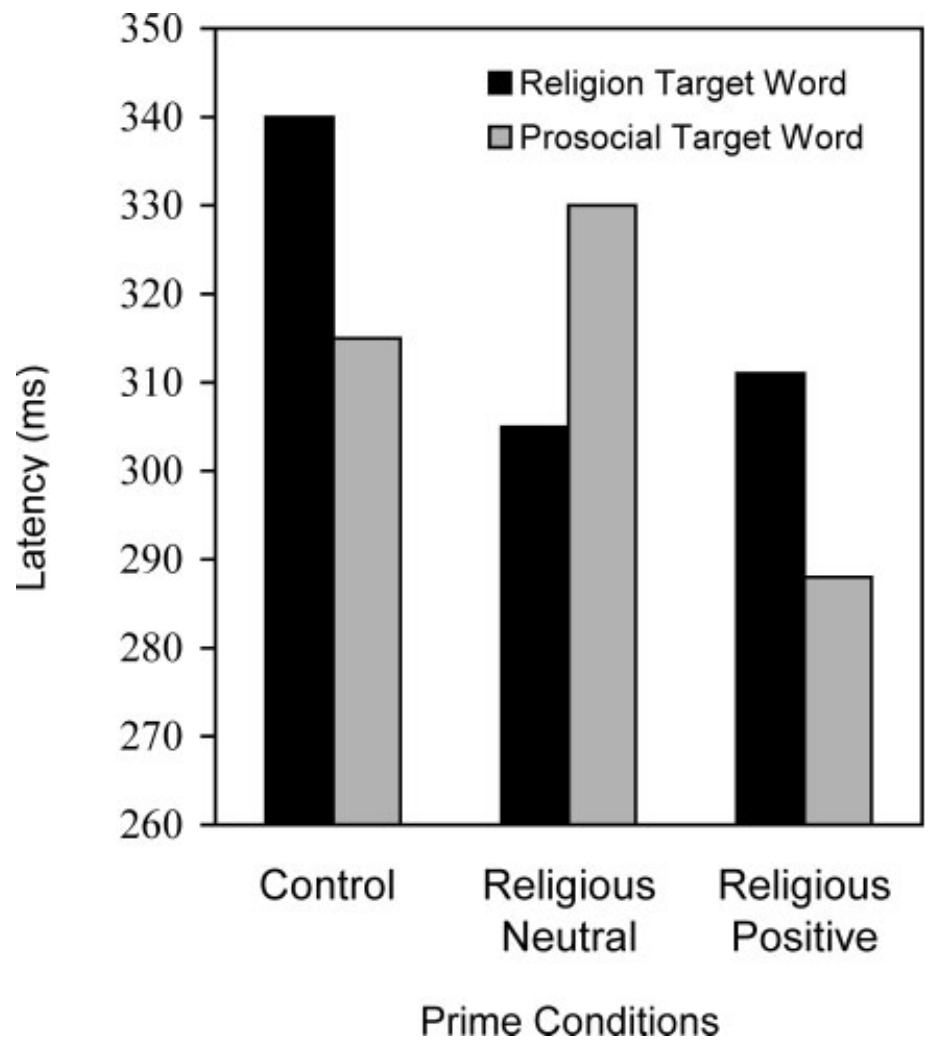

Figure 2. Reaction time (in milliseconds) for religion and prosocial target words depending on prime type (Study 2)

although separate comparisons between positive religion priming and either control, $t(1,35)=-1.03$, $p=.15$, or neutral religious priming, $t(1,35)=-1.38, p=.08$, on accessibility of prosocial words did not reach significance, combining the two latter neutral (religious and non-religious) conditions $(M=$ $322.46, S D=101.14$ ) allowed us to confirm the higher accessibility of prosocial words after positive religious priming, $t(1,55)=-1.59, p=.03$. Finally, the latencies for recognition of the filler words were not different $(t(1,55)=1.18$, n.s. $)$ when we compared the positive religious condition $(M=$ $336.50, S D=97.72)$ to the two neutral conditions $(M=376.01, S D=121.75)$, nor when we compared the two religious conditions $(M=354.73, S D=90.85)$ to the non-religious neutral condition $(M=$ $381.80, S D=152.68), t(1,55)=0.73$, n.s.

The results of Study 2 thus confirmed our expectations. Indeed, while religion priming — neutral and positive - activates religion-related items, positive religion priming also increases the accessibility of prosociality-related items. Thus, Study 2 is in line with and extends Study 1: only the positive side of religion is able to activate prosociality; and this effect means activation of both a prosocial behavioral schema and a prosocial concept. Future research should investigate whether what was found in Study 2 may explain the results of Study 1: positive religious priming nonconsiously activates the concept of prosociality (or to put it in other words, activates the stereotypical association between religion and prosociality), and this activation may nonconsciously lead people to express at least some behavioral intentions. Finally, although the data are in line with our hypothesis - prosociality seems more accessible after the priming of positive religious concepts compared to neutral religious concepts, 
there is still some ambiguity in our data. Although not quite significantly, positive religion also reduced the latencies for the filler words. Possibly due to floor effects, within group comparisons do not support the pattern of the between group comparison. However, given that this study was conducted to further investigate the between group effects of Study 1, we focus on the between group results.

\section{GENERAL DISCUSSION}

Across many religions and cultures, the idea of religiousness evokes positive images of charity and altruism. Previous research using explicit measures correlating religiousness with prosociality has provided many interesting results and a rather complex picture (Batson et al., 1993, 2005; Saroglou, 2006) but it also presents some obvious limitations: the explicit measures used in previous studies are subject to self-presentation and self-control biases, and the correlational evidence of that research does not allow us to infer anything about possible direction(s) of influence.

In attempting to overcome these problems, in the present studies we used 'religion' as an independent variable and showed that priming at least positive religion (with subliminal and supraliminal techniques) activates both behavioral schemas and concepts related to prosociality. These results suggest, first, that the association between religion (or at least some of its aspects) and prosociality is rather deep, going beyond people's conscious awareness and, by extension, beyond social desirability or other self-presentation biases under the person's cognitive control. Second, they provide evidence in favor of the idea that besides the correlational evidence of previous studies one can seriously conceive of at least one direction of causality, that is, religion as affecting prosocial representations and behavioral schemas in some way. Such a pattern of results thus offers tentative experimental evidence in favor of what is a common assumption in most psychological theories of religion, namely that religion's role on the individual and social level includes an emphasis on prosociality.

Interestingly, in both studies, increase of prosociality emerged only in the case of positive religion priming, whereas priming religious elements neutral in valence did not activate prosocial concepts or behavioral intentions. These results indicate that religion is a complex representation and only its positive side evokes prosocial images. The impact of positive religion on prosociality is probably ascribable to the combination of valence with religious ideals and norms, thus making positive religion a powerful inciter of prosociality. Going even further, it is not to be excluded that negative aspects of religion may have a negative impact on activation of prosocial concepts and corresponding behaviors. For instance, previous correlational research has shown that negative God representations (such as the image of a punitive God) are linked to authoritarian and punitive styles of education in the family (Lambert, Triandis, \& Wolf, 1959; Potvin, 1977). Similarly, one should not conclude from our study that religion in general, or even positive religion in particular, leads only to increased prosociality. In some contexts, priming religion, again even positive aspects of it, may be ineffective for activating prosocial behavior schemas: summarizing previous research and their own studies, Saroglou et al. (2005; Saroglou, 2006) concluded that the positive role religion seems to play with regard to prosociality is manifest only within in-group borders or at least only when an in- versus out-group distinction has not been activated.

The present findings also confirm and extend research on automaticity in social behavior in general (Brown, Croizet, Bohner, Fournet, \& Payne, 2003; Djksterhuis \& Bargh, 2001) and prosocial behavior, in particular, where prosociality in self-perceptions, intentions, or behaviors was increased following different kinds of supraliminal priming of prosociality (construct of helpfulness: Macrae \& Johnson, 1998; category of superhero: Nelson \& Norton, 2005; and altruistic words: Walther, Müller, \& Schott, 
2001). Our study extends this previous research by showing that priming constructs non-directly related to prosociality such as religion can also affect prosocial perceptual or behavioral outcomes. It also provides evidence that subliminal — and not only supraliminal, as in previous studies — priming affects prosocial intentions.

Subsequent research should investigate what can be considered as limitations of the present studies. First, if religious priming increases prosocial intentions and accessibility of prosocial concepts, future experiments are needed to test whether this effect may be extended to natural settings involving real prosocial behavior. Second, although there is evidence that the link between religion or religiousness and a variety of prosocial realities (personality, values, behaviors, and religious ideals) is rather consistent across religions, countries, and cohorts (Saroglou, in press), one should not neglect the Christian, and more specifically Catholic, background of participants in our study. A replication in other religious contexts is necessary before findings can be generalized.

Finally, questions worthy of future investigation arise from the present study. First, did the religious prime have an impact on all participants or only on people who were themselves religious? Previous research provides contradictory suggestions. On one hand, automatic category activation has been found to have divergent effects as a function of pre-existing attitudes (e.g., Brown et al., 2003); and the effect priming values shows on consequent choices and behavior depends on whether these values are central to the self-concept (Verplanken \& Holland, 2002). Similarly, the nonconscious influence of religious stimulation seems to concern only or mainly religious participants (Weisbuch-Remington et al., 2005; Wenger, 2004), possibly because the latter tend to internalize their beliefs and values, and try to live according to them (Wenger, 2004) or because religious symbols are personally relevant to these participants (Weisbuch-Remington et al., 2005). On the other hand, research on priming also suggests that priming effects often work independently of, or even contrary to pre-existing personal dispositions related to the priming construct (e.g., Gardner, Gabriel, \& Lee, 1999). Similarly, religious stimulation was found to decrease propensity for, and indeed inhibit spontaneous humor creation (Saroglou \& Jaspard, 2001), a finding obtained from students that were far from all being religious. In the two present studies, it is likely then that the effect of religious priming was due to, or was stronger among religious participants, but it is not to be excluded that the effect was also present among the non-religious ones, since young Belgians - whether socialized as Catholic or not- have grown up in a society that provides a religious culture emphasizing prosocial ideals and values.

Second, another question is whether the present results can be generalized to priming not only with religious concepts of 'universal' relevance (among the words we used, see e.g., spirituality, belief, faith) or from Christian tradition (among the words we used, see e.g., Christmas, heaven, soul), but with religious concepts from other religious traditions, such as Judaism, Islam, or Buddhism. It seems reasonable to hypothesize that religious concepts from other traditions that have positive connotations - for instance, for Christian participants - may also have some impact on activation of prosociality. Interestingly, with regard to this point, Norenzayan and Hansen (2006) found that, among Christians, mortality salience increase not only religious beliefs in reference to one's own tradition, but also religious beliefs in reference to alien religious traditions (e.g., Buddhism and Shamanism). However, it is not to be excluded that concepts from other religious traditions that have negative connotations and/or are perceived as markers of in- versus out-group differences (see e.g., 'the Pope' for Orthodox and Protestants, or 'Jihad' for non-Muslims) do not activate prosociality or even activate opposite social constructs.

Finally, an exciting question for future research is: what were the underlying psychological mechanisms explaining our results? One can hypothesize, for instance, that positive religious priming increased accessibility of prosocial concepts and expression of prosocial behavioral intentions because religion, especially its positive aspects, includes or reflects: self-transcendence values, such as benevolence (Saroglou et al., 2004), religious models and figures of charity and altruistic sacrifice 
(James, 1902/1985), a historical 'stereotype' of a religion-prosociality association, and/or an emphasis on the importance of perceiving oneself as altruistic (Batson et al., 1993). Interestingly, in the priming literature, including literature on the priming of helping and prosocial behavior, there is evidence that the activation of these psychological realities (values: Verplanken \& Holland, 2002; models: Nelson \& Norton, 2005; knowledge structures such as stereotypes: Higgins, 1996; or self-activation: Utz, 2004) can lead to corresponding social perception and behavior. Studying such underlying processes of the religious prime-prosociality association could enhance our understanding of a complex psychological reality that has significant social consequences in our day.

\section{ACKNOWLEDGEMENTS}

The authors are thankful to Olivier Corneille, Michaela Wänke (associate editor), and three anonymous reviewers for their insightful comments on previous versions of the manuscript. This research was part of the doctoral thesis of the first author and was funded by a grant from the Fonds spéciaux de recherche of the Université catholique de Louvain attributed to the first and third author. During this research, the second author was working on his doctoral thesis with a fellowship from the Action de Recherche Concertée \# 01/06-270 of the Communauté Française de Belgique and the Université catholique de Louvain.

\section{REFERENCES}

Baldwin, M. W., Carrell, S. E., \& Lopez, D. F. (1990). Priming relationship schemas: My advisor and the Pope are watching me from the back of my mind. Journal of Experimental Social Psychology, 26, 435-454.

Bargh, J. A. (2006). What have we been priming all these years? On the development, mechanisms, and ecology of nonconscious social behavior. European Journal of Social Psychology, 36, 147-168.

Bargh, J. A., Chen, M., \& Burrows, L. (1996). Automaticity of social behavior: Direct effects of trait construct and stereotype activation on action. Journal of Personality and Social Psychology, 71, 230-244.

Bargh, J. A., Gollwitzer, P. M., Lee-Chai, A., Barndollar, K., \& Trotschel, R. (2001). The automated will: Nonconscious activation and pursuit of behavioral goals. Journal of Personality and Social Psychology, 81, 1014-1027.

Batson, C. D. (1983). Sociobiology and the role of religion in promoting prosocial behavior. Journal of Personality and Social Psychology, 45, 1380-1385.

Batson, C. D., Anderson, S. L., \& Collins, E. (2005). Personal religion and prosocial motivation. In M. L. Maher, \& S. A. Karabenick (Eds.), Motivation and religion (special issue). Advances in motivation and achievement (Vol. 14, pp. 151-185). Greenwich, CT: JAI Press.

Batson, C. D., Schoenrade, P., \& Ventis, W. L. (1993). Religion and the individual: A social-psychological perspective. New York: Oxford University Press.

Brown, R., Croizet, J. -C., Bohner, G., Fournet, M., \& Payne, A. (2003). Automatic category activation and social behavior: The moderating role of prejudiced beliefs. Social Cognition, 21, 167-193.

Cohen, J. D., MacWhinney, B., Flatt, M., \& Provost, J. (1993). PsyScope: A new graphic interactive environment for designing psychology experiments. Behavioral Research Methods, Instruments, \& Computers, 25, 257271.

de Dreu, C. K. W., Yzerbyt, V., \& Leyens, J. -P. (1995). Dilution of stereotype-based cooperation in mixed-motive interdependence. Journal of Experimental Social Psychology, 31, 575-593.

Dijksterhuis, A., \& Bargh, J. A. (2001). The perception-behavior expressway: Automatic effects of social perception on social behavior. In M. P. Zanna (Ed.), Advances in experimental social psychology (Vol. 33, pp. 1-40). New York: Academic Press.

Dijksterhuis, A., \& van Knippenberg, A. (1998). The relation between perception and behavior, or how to win a game of trivial pursuit. Journal of Personality and Social Psychology, 74, 865-877.

Erikson, E. H. (1963). Childhood and society (2nd ed.). New York: Norton. 
Fazio, R. H., \& Olson, M. A. (2003). Implicit measures in social cognition research: Their meaning and use. Annual Review of Psychology, 54, 297-327.

Freud, S. (1972/1961). The future of an illusion (J. Strachey, Trans.). New York: Norton.

Gardner, W. L., Gabriel, S., \& Lee, A. Y. (1999). 'I' value freedom, but 'we' value relationships: Self-construal priming mirrors cultural differences in judgment. Psychological Science, 10, 321-326.

Higgins, E. T. (1996). Knowledge activation: Accessibility, applicability, and salience. In E. T. Higgins, \& A. W. Kruglanski (Eds.), Social psychology: Handbook of basic principles (pp. 133-168). New York: Guilford Press.

Hunsberger, B., \& Jackson, L. M. (2005). Religion, meaning, and prejudice. Journal of Social Issues, 61, 807-826.

Jackson, L. M., \& Esses, V. M. (1997). Of scripture and ascription: The relation between religious fundamentalism and intergroup helping. Personality and Social Psychology Bulletin, 23, 893-906.

James, W. (1902/1985). The varieties of religious experience: A study in human nature. Cambridge, MA: Harvard University Press.

Kirkpatrick, L. A. (2005). Attachment, evolution, and the psychology of religion. New York: Guilford Press.

Lambert, W. W., Triandis, L. M., \& Wolf, M. (1959). Some correlates of beliefs in the malevolence and benevolence of supernatural beliefs: A cross-societal study. Journal of Abnormal and Social Psychology, 58, $162-169$.

Macrae, C. N., \& Johnson, L. (1998). Help, I need somebody: Automatic action and inaction. Social Cognition, 16, 400-417.

Nelson, L. D., \& Norton, M. I. (2005). From student to superhero: Situational primes shape future helping. Journal of Experimental Social Psychology, 41, 425-430.

Norenzayan, A., \& Hansen, I. G. (2006). Belief in supernatural agents in the face of death. Personality and Social Psychology Bulletin, 32, 174-187.

Potvin, R. H. (1977). Adolescent God images. Review of Religious Research, 19, 43-53.

Saroglou, V. (2002). Religion and the five factors of personality: A meta-analytic review. Personality and Individual Differences, 32, 15-25.

Saroglou, V. (2006). Religion's role in prosocial behavior: Myth or reality? Psychology of Religion Newsletter: American Psychological Association Division 36, 31, 1-8.

Saroglou, V. (in press). Religion and personality: A big five factor perspective. In D. Wulff (Ed.), Handbook of psychology of religion. New York: Oxford University Press.

Saroglou, V., Delpierre, V., \& Dernelle, R. (2004). Values and religiosity: A meta-analysis of studies using Schwartz's model. Personality and Individual Differences, 37, 721-734.

Saroglou, V., \& Jaspard, J. -M. (2001). Does religion affect humour creation? An experimental study. Mental Health, Religion, and Culture, 4, 33-46.

Saroglou, V., Pichon, I., Trompette, L., Verschueren, M., \& Dernelle, R. (2005). Prosocial behavior and religion: New evidence based on projective measures and peer-ratings. Journal for the Scientific Study of Religion, 44, 323-348.

Skinner, B. F. (1969). Contingencies of reinforcement: A theoretical analysis. New York: AppletonCentury-Crofts.

Trimble, D. E. (1997). The religious orientation scale: Review and meta-analysis of social desirability effects. Educational and Psychological Measurement, 57, 970-986.

Utz, S. (2004). Self-activation is a two-edged sword: The effects of I primes on cooperation. Journal of Experimental Social Psychology, 40, 769-776.

Verplanken, B., \& Holland, R. W. (2002). Motivated decision making: Effects of activation and self-centrality of values on choices and behaviors. Journal of Personality and Social Psychology, 82, 434-447.

Walther, E., Müller, D., \& Schott, O. (2001). Automatic social behavior: How does priming of egoism and altruism influence helping behavior? [in German]. Zeitschrift für Experimentelle Psychologie, 48, 248-257.

Weisbuch-Remington, M., Mendes, W. B., Seery, M. D., \& Blascovitch, J. (2005). The nonconscious influence of religious symbols in motivated performance situations. Personality and Social Psychology Bulletin, 31, 1203-1216.

Wenger, J. L. (2004). The automatic activation of religious concepts: Implications for religious orientations. International Journal for the Psychology of Religion, 14, 109-123.

Wittenbrink, B., Judd, C. M., \& Park, B. (1997). Evidence for racial prejudice at the implicit level and its relationship with questionnaire measures. Journal of Personality and Social Psychology, 72, 262-274.

Wittenbrink, B., Judd, C. M., \& Park, B. (2001). Evaluative versus conceptual judgments in automatic stereotyping and prejudice. Journal of Experimental Social Psychology, 37, 244-252. 


\section{APPENDIX A}

Words used for subliminal priming (Study 1)

\begin{tabular}{|c|c|c|}
\hline & Religious words & Non-religious words \\
\hline \multirow{20}{*}{ Positive } & Heaven (paradis) & Freedom (liberté) \\
\hline & Miracle (miracle) & Meeting (rencontre) \\
\hline & Wedding (mariage) & Dynamism (dynamisme) \\
\hline & Spirituality (spiritualité) & Tolerance (tolérance) \\
\hline & Angel (ange) & Flower (fleur) \\
\hline & Praise (louange) & Reconciliation (réconciliation) \\
\hline & Baptism (baptême) & Thanks (remerciements) \\
\hline & Tradition (tradition) & Birth (naissance) \\
\hline & Aureole (auréole) & Sympathy (sympathie) \\
\hline & Salvation (salut) & Amusement (amusement) \\
\hline & Soul (âme) & Optimism (optimisme) \\
\hline & Beatitude (béatitude) & Smile (sourire) \\
\hline & Christmas (Noël) & Sun (soleil) \\
\hline & Belief (croyance) & Children (enfants) \\
\hline & Bless (bénir) & Imagination (imagination) \\
\hline & Faith (foi) & Charm (charme) \\
\hline & Temple (temple) & Strength (force) \\
\hline & Pilgrimage (pèlerinage) & Balance (équilibre) \\
\hline & Prayer (prière) & Salary (salaire) \\
\hline & Communion (communion) & Chance (chance) \\
\hline \multirow[t]{20}{*}{ Neutral } & Mitre (mitre) & Shirt (chemise) \\
\hline & Monk (moine) & Butter (beurre) \\
\hline & Steeple (clocher) & Switch (interrupteur) \\
\hline & Bishop (évêque) & Hammer (marteau) \\
\hline & Sacrament (sacrement) & Cardboard (carton) \\
\hline & Missal (missel) & Ladder (échelle) \\
\hline & Holy-water stoup (bénitier) & Bag (sacoche) \\
\hline & Ordination (ordination) & News (actualité) \\
\hline & Parish (paroisse) & Diary (calendrier) \\
\hline & Apostle (apôtre) & Flour (farine) \\
\hline & Bible (bible) & Cloud (nuage) \\
\hline & Priest (prêtre) & Stairs (échelle) \\
\hline & Rosary (chapelet) & Rhyme (rime) \\
\hline & Disciple (disciple) & Sandal (sandale) \\
\hline & Incense (encens) & Handkerchief (mouchoir) \\
\hline & Chapel (chapelle) & Office (bureau) \\
\hline & Solemn (solennel) & Glue (colle) \\
\hline & Genesis (genèse) & Cupboard (armoire) \\
\hline & Altar (autel) & Disc (disque) \\
\hline & Host (hostie) & Banana (banane) \\
\hline
\end{tabular}

Note: The original French words used in the experiment are in parentheses. 


\section{APPENDIX B}

Words used for the lexical decision task (Study 2)

\begin{tabular}{lll}
\hline Religious words & Prosocial words & Neutral words \\
\hline Angel (ange) & Help (aide) & Rhyme (rime) \\
Aureole (auréole) & Agreeableness (amabilité) & Bag (sacoche) \\
Belief (croyance) & Collaboration (collaboration) & News (actualité) \\
Miracle (miracle) & Kindness (gentillesse) & Ladder (échelle) \\
Christmas (Noël) & Support (soutien) & Switch (interrupteur) \\
Heaven (paradis) & Support (support) & Cupboard (armoire) \\
Comfort (réconfort) & Sympathy (sympathie) & Shirt (chemise) \\
\hline
\end{tabular}

Note: The original French words used in the experiment are in parentheses. 
Copyright of European Journal of Social Psychology is the property of John Wiley \& Sons Ltd. 1996 and its content may not be copied or emailed to multiple sites or posted to a listserv without the copyright holder's express written permission. However, users may print, download, or email articles for individual use. 